\title{
Design of horizontal shear strain instrument for co-estimation of soil stress-strain
}

\author{
Chompoonud Kulketwong ${ }^{1}$, and Dithaporn Thungsotanon ${ }^{1 *}$ \\ ${ }^{1}$ King Mongkut's Institute of Technology Ladkrabang, Prince of Chumphon, Department of \\ Engineering, Chumphon, Thailand
}

\begin{abstract}
This study aimed to design and fabricate the horizontal shear strain transducer (HST) for measuring the soil strain under the agricultural machinery traffic by using a rotary potentiometer which was an angular strain change detector. The angular movable mechanism was calibrated and evaluated the characteristics of the instrument in the laboratory, and found that the non-linearity and the hysteresis were 4.56 and $4.42 \%$, respectively. Furthermore, the strain measurement device was buried in the field to compare the shear strain at varying tractor velocities $(5,6.5$ and $8 \mathrm{~km} / \mathrm{h})$. For all vehicle speed at the first passage, the shear strain and soil bulk density obviously increased, whereas the final moisture content decreased; as a result, the lower velocity caused higher shear strain.
\end{abstract}

\section{Introduction}

Soil compaction from the heavyweight agricultural machinery is a necessary factor to take into consideration. If the external force is greater than the soil strength or the load is applied over and over again, the soil structure deforms and finally leads compaction that causes the plant roots reduce the nutrient absorption. When the agricultural vehicle traffic on the terrain, the compaction and degradation of the topsoil are clearly visible from the sink trace. However, the deformation of the subsoil is not easy to observe and taking longer to show up.

The soil bulk density, cone index and infiltration rate have preferred to measure the insitu soil compaction. These methods are only verified their effects, but the data are not backward analyzed to assess the external dynamic forces that affect the soil structure. For understanding this response, the dynamic stress-strain relationship is mentioned describing the internal structure of soil due to the external dynamic force.

The in-situ complete stress was measured with the stress state transducer (SST) that was presented by Nichols et al. [1] and widely used in the investigation of the dynamic stress behavior [2-6]. The methods for determination of the strain and the soil compaction using the SST have been being developed by many researchers [7-9]. The soil strain was measured by a several means, for instance, the linear displacement sensor, linear potentiometer, laser projector and video camera that worked with the link mechanism for examining the linear and angular displacement of soil. Wiermann et al. [10] took the displacement transducer system (DTS) associated with the SST to estimate the soil movement while the machinery

* Corresponding author: dithaporn.th@kmitl.ac.th 
that had the various dynamic loads moved and indicated that the soil was displaced in both vertical and horizontal directions. The linear potentiometer was mounted at the end-plate and put down following the mutually orthogonal system [11]. From this procedure, there was no significant difference between the bulk density that measured by the potentiometer and the core sampling. The non-contact technique by the laser projector could show the position of the motion of mechanism and was recorded with the VDO camera, so Pytka [12] and Pytka and Konstankiewicz [7] used this method to collaborate with the SST both laboratory and field testing.

As mentioned above, the mechanical responding behavior of soil in terms of stress and strain should be estimated simultaneously and it was the important parameter for study the interaction of wheel-agricultural soil system. This article presents the technique for measuring the shear strain and lateral soil deformation, because of the shear force was applied to the soil structure, associated with the complete stress measurement by using the SST. The procedure was divided into two parts: the laboratory and the field testing.

\section{Materials and methods}

\subsection{Design of the horizontal shear strain transducer (HST)}

The horizontal shear strain transducer (HST) as shown in Figure 1(a) was designed to operate with the stress state transducer (SST), in Figure 1(b), that was developed from the concept of Nichols et al. [1]. The HST was rotated by the U-shape mechanism that made from the stainless rod and mounted the rotary potentiometer (HR Electronics, WDD35D4 model) with a resistance of $10 \mathrm{k} \Omega \pm 15 \%$ and the $0.1 \%$ of non-linearity error. The angular displacement detected by the HST - showed the analog output signal in a range of 0-5 VDC and was collected to the data acquisition (NI 9205, National Instrument) and then the data was transmitted to the computer that associate with the SignalExpress 2014 software for processing, monitoring and recording via WI-FI.

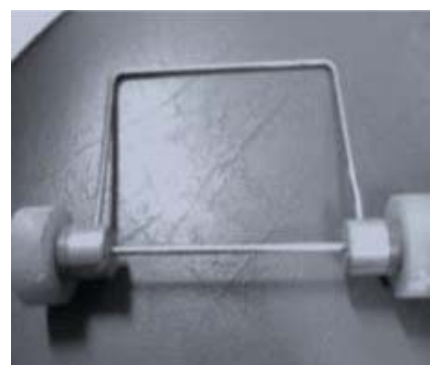

(a) HST

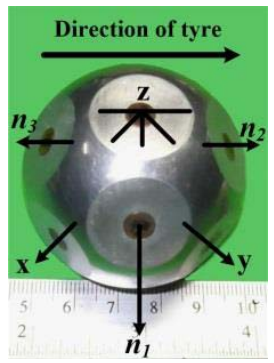

(b) SST

Fig. 1. Instrument unit for measure stress-strain relations in soils.

Then, the HST was calibrated and the error of non-linearity and hysteresis were determined and shown as Equation (1).

$$
\theta=m V
$$

Where $\theta$ is the angular displacement $\left(^{\circ}\right), m$ is the slope (Dimensionless) and $V$ is the output voltage $(\mathrm{V})$. 


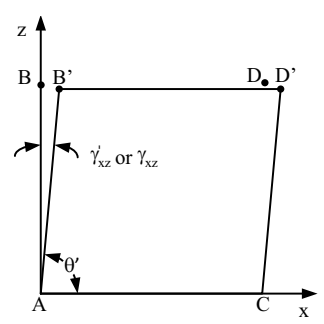

Fig. 2. Soil element deformation due to shear strain.

After that, the non-linearity error, hysteresis error and the slope of the linear regression showed $4.56 \%, 4.42 \%$ and 71.58 , respectively. For the soil element mobility analysis, the deformed body of rotation movement under loading was indicated as Figure 2 and followed as Equation (2).

$$
\theta^{\prime}=\frac{\pi}{2}-\gamma_{x z}
$$

Where $\theta^{\prime}$ is the angle of deformed body (rad) and $\gamma_{x z}$ is the angel of shear strain (rad).

\subsection{Laboratory testing}

The burying of HST at $15 \mathrm{~cm}$ depth was divided into two conditions, as shown in Figure 3(a) and (b), in the soil box that contained the sand soil (sand $90.75 \%$, silt $7.51 \%$ and clay $1.74 \%$ ) which of the moisture content of $10 \%$ and the bulk density of $1.0 \mathrm{~g} / \mathrm{cm}^{3}$. From Figure $3(\mathrm{a})$, the two sets of HST were horizontal laid $15 \mathrm{~cm}$ afar. The vertical pressure that imitated the wheel or track traffic was applied to the soil surface at the center, a quarter and three-quarters from the HST center. Whereas, the schematic of Figure 3(b) showed the HST was buried at a half of soil box and the pressure from the circular plate that inclined with $30^{\circ}$ and $45^{\circ}$ was compressed with the speed of $20 \mathrm{kPa} / \mathrm{min}$.

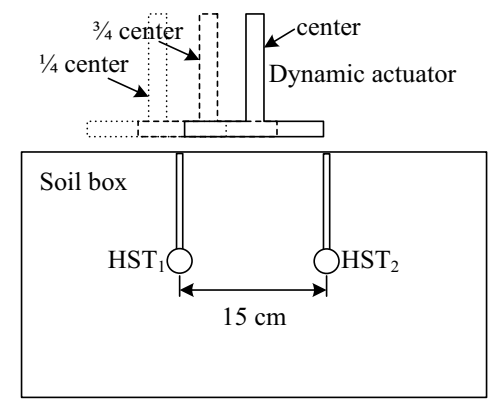

(a) Conventional method

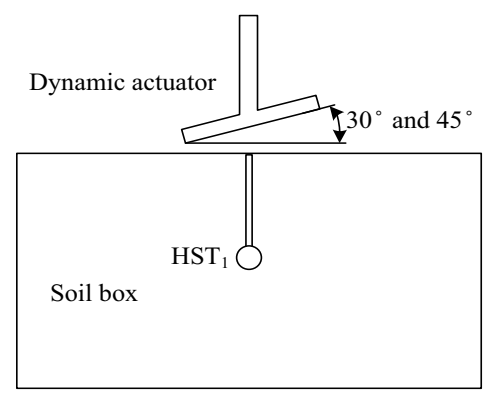

(b) Inclined method

Fig. 3. Schematic of experimental setup.

The soil samples were estimated the initial bulk density at the depth of 15 and $30 \mathrm{~cm}$ from surface during processed. When the dynamic loading was performed, the angular shear strain differential rate on the horizontal plane was recorded at the speed of $1 \mathrm{kHz}$. After testing, the 
top soil was opened carefully for avoiding direct contact to the mechanism and the HST was determined the degree of rotation by the marking scale.

\subsection{Field testing}

The two pieces of HST were buried, similar to the first condition of laboratory experiment, in the hole that followed the concepts of Eguchi and Muro [3] and Pytka and Konstankiewicz [7] and the SST was placed at the middle of them (Figure 4). Then, filled the hole and compacted the soil in order to the initial bulk density was equal to the laboratory value and cured it overnight. The soil moisture content and bulk density were estimated both before and after testing.

The 2WD tractor (Ford-New Holland 6610) that had the 7.50-16 front wheels and the 18.4-30 rear wheels with the inflation pressure of $179.26 \mathrm{kPa}(26 \mathrm{psi})$ and the velocity of 5 , 6.5 and $8 \mathrm{~km} / \mathrm{h}$ was moved over the testing area (Figure 5). Therefore, the output signals of the two HST and SST were transmitted to acquisition for the same processing as the section 2.1 .

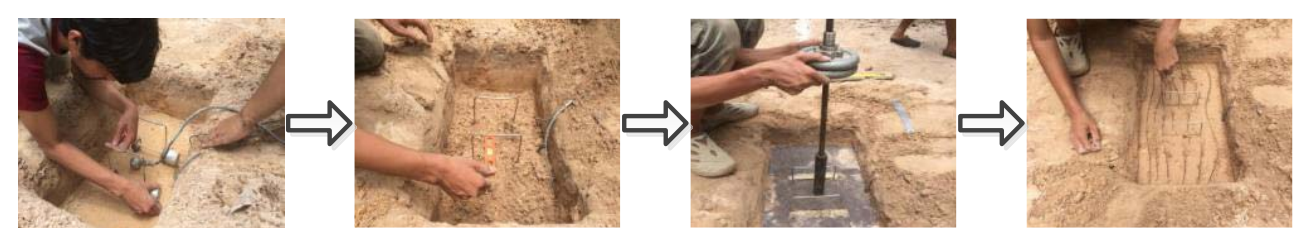

Fig. 4. Field device installation and configuration.

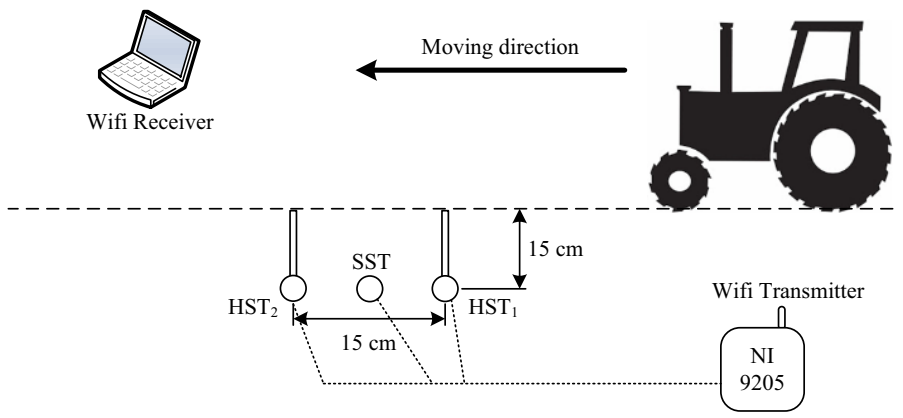

Fig. 5. The transport moved over the HST and SST.

\section{Results and discussion}

For the HST testing, we would like to present the results into 2 parts: the mechanism of HST did viable and accuracy work (in the section 3.1) and the effect of the vehicle speed on the soil compaction in the field test (in the section 3.2).

\subsection{Validation and evaluation the HST}

From Figure 3(a), the first set of the HST $\left(\mathrm{HST}_{1}\right)$ was eccentricity offset compressed to examine the movement of both $\mathrm{HST}_{1}$ and $\mathrm{HST}_{2}$. The results showed that the initial applied pressure, from the circular plate at the center, was less and the rotation angle of HST remained 
unchanged until the compression force reached to $40 \mathrm{kPa}$, the angular displacement would be increased ( $\left.\mathrm{HST}_{2}\right)$ and decreased ( $\mathrm{HST}_{1}$ ) stability in the range of 130-300 s (Figure 6).

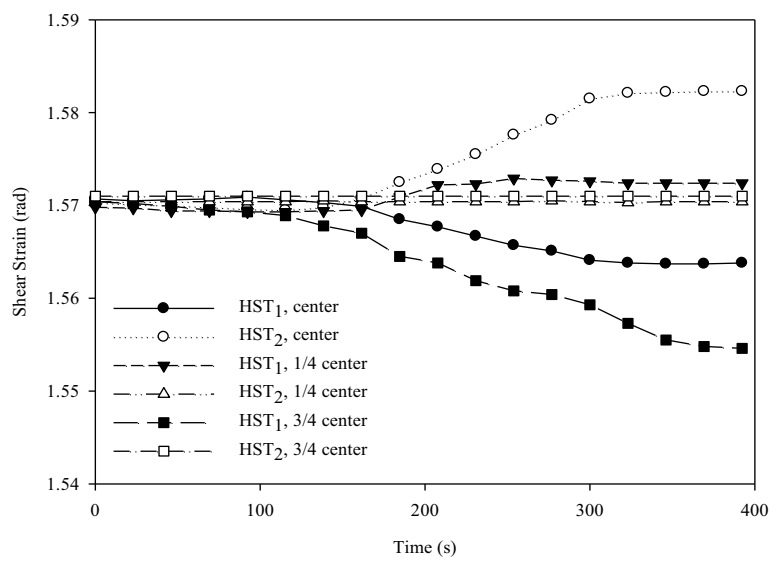

Fig. 6. Modelling of soil surface compaction from $\mathrm{HST}_{1}$ at different compressed positions.

The values of the 2 HSTs in Figure 6 were manifested opposite directions due to the lateral soil movement [11]. At the one quarter from the center of the soil box, the circular plate could cover the left and right of the $\mathrm{HST}_{1}$ (Figure 3(a)) and found that the most soil surface around the $\mathrm{HST}_{1}$ was strongly vertical sank and the occurrence of the lateral displacement appeared slightly when the higher load was applied. On the other hand, the $\mathrm{HST}_{2}$ unmoved owing to it was placed outside the soil failure zones [13]. However, the displacement of the $\mathrm{HST}_{1}$ was increased when the plate compressed the soil at the threefourths from the center.

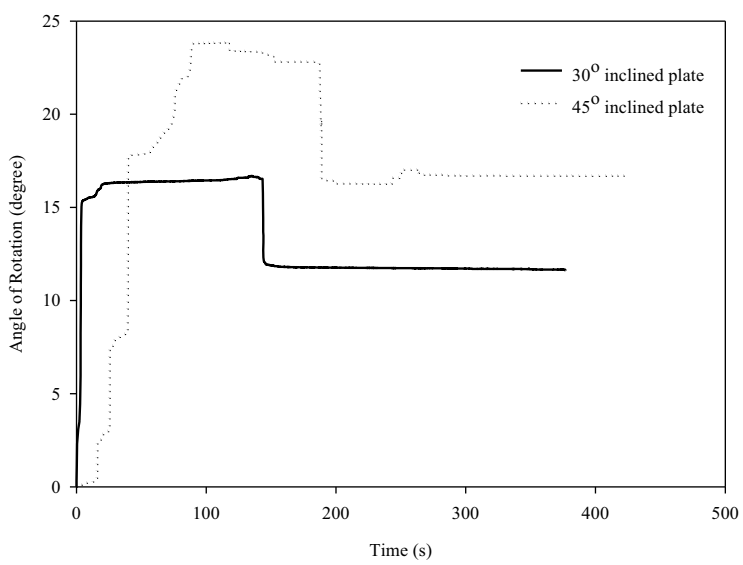

Fig. 7. Estimation of the angle of rotation of HST when compressed by the inclined plate.

The Figure 7 showed the result of compressing the $30^{\circ}$ and $45^{\circ}$ of inclined plate (in Figure 3(b)) and indicated that the slope of the contact area affected the increasing of the lateral soil deformation [14] and the inclined angle was higher, the value of HST was great too. The horizontal displacement appeared the high value from the beginning of compressing because of the U-link (as shown in Figure 1(a)) was laid closely the soil surface. The HST 
was moved along with the soil mass that was drawn up with the inclined plate. After that, the displacement was steady until the maximum pressure. On the contrary, the loading process caused the soil mass not only released, but the rotation angle also reduced. The angles of inclination of the plate $30^{\circ}$ and $45^{\circ}$ after experiment were $11.6^{\circ}$ and $16.7^{\circ}$, respectively. Then, the soil surface was dug carefully and examined the marking scale of the HST and found that the error between the observed values and the sensor values showed $5.4 \%$ and $4.4 \%$ for the $\mathrm{HST}_{1}$ and the HST 2 , respectively. Therefore, the HST mechanism and the concept of angular displacement enabled to measure the lateral soil deformation from the dynamic load.

\subsection{Velocity effects upon soil properties and stress-strain relations}

For the field testing, the sand soil after the tractor travelled was found that the moisture content decreased, whereas the bulk density increased in every velocity (as shown in Table 1). In fact, the speed of the vehicle could not obviously describe the effect on the soil moisture content and the soil bulk density since the initial moisture content in nature could not prepare equally for every condition.

Table 1. Soil moisture content and bulk density at the varying of tractor speed.

\begin{tabular}{|c|c|c|c|c|}
\hline \multirow{2}{*}{ Velocity $(\mathrm{km} / \mathrm{h})$} & \multicolumn{2}{|c|}{ Soil moisture content \pm S.D. $(\% \mathrm{db})$} & \multicolumn{2}{c|}{ Bulk density \pm S.D. $\left(\mathrm{g} / \mathrm{cm}^{3}\right)$} \\
\cline { 2 - 5 } & Before traffic & After Traffic & Before traffic & After traffic \\
\hline 5.0 & $10.12^{\mathrm{C}} \pm 0.11$ & $10.07^{\mathrm{C}} \pm 0.10$ & $0.94^{\mathrm{A}} \pm 0.01$ & $1.04^{\mathrm{A}} \pm 0.01$ \\
\hline 6.5 & $9.27^{\mathrm{B}} \pm 0.56$ & $8.93^{\mathrm{B}} \pm 0.53$ & $0.98^{\mathrm{B}} \pm 0.02$ & $1.08^{\mathrm{B}} \pm 0.00$ \\
\hline 8.0 & $8.20^{\mathrm{A}} \pm 0.21$ & $7.82^{\mathrm{A}} \pm 0.40$ & $0.96^{\mathrm{AB}} \pm 0.01$ & $1.11^{\mathrm{C}} \pm 0.01$ \\
\hline
\end{tabular}
level.

However, the agricultural operation with the heavyweight machinery still impacted the decreasing of pore space size and soil-water content. These were the important factors that should take into consideration on the use of the farm tractor and equipment in the plantation including the appropriate selection of the vehicle velocity was able to alleviate the compacted soil that affected the root growth.

Investigation of the stress-strain relationship during the vehicle moving was the crucial approach to understanding the soil mechanics. From the tractor speed results, the complete stress from the SST was interpreted in terms of the stress on the octahedral plane. $\sigma_{\text {oct }}$ defined as the soil under compression and $\tau_{\text {oct }}$ was the soil under shearing condition. The result of the HST was described in the form of the deformed cube due to the dynamic load (in Figure 5). From Figure 8, when the front wheel and the rear wheel moved over the SST and the HST, the stresses showed the behavior of compression and shear simultaneously. While the front wheel passed the devices, the shear stress showed higher value than the compressive stress and accorded with the values of the deformed body at the $\mathrm{HST}_{1}$ and $\mathrm{HST}_{2}$ that rapid increase. This effect indicated that the soil mass before the external loading had intensely compressed and lateral slipped, whereas the deformed cube rates on the rear wheel were less than the front wheel and the same phenomena occurred in every tractor speed. The soil response behavior was observed the stress preceded the strain that meant when the external load was applied and exceeded the soil strength, the soil mass was changed its structure and finally failure. 


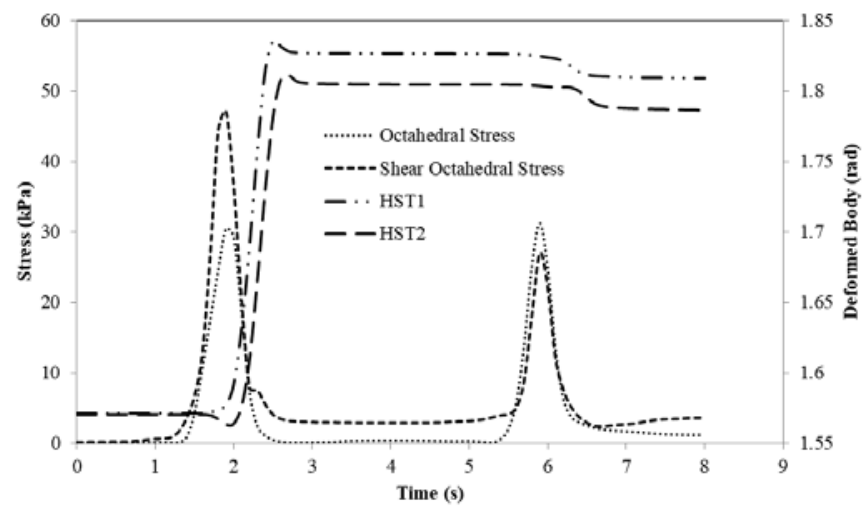

Fig. 8. The relationship of the octahedral stress $\left(\sigma_{\text {oct}}, \tau_{\text {oct }}\right)$ and the deformed body of $\mathrm{HST}_{1}$ and $\mathrm{HST}_{2}$ during the tractor travelled with $5 \mathrm{~km} / \mathrm{h}$.

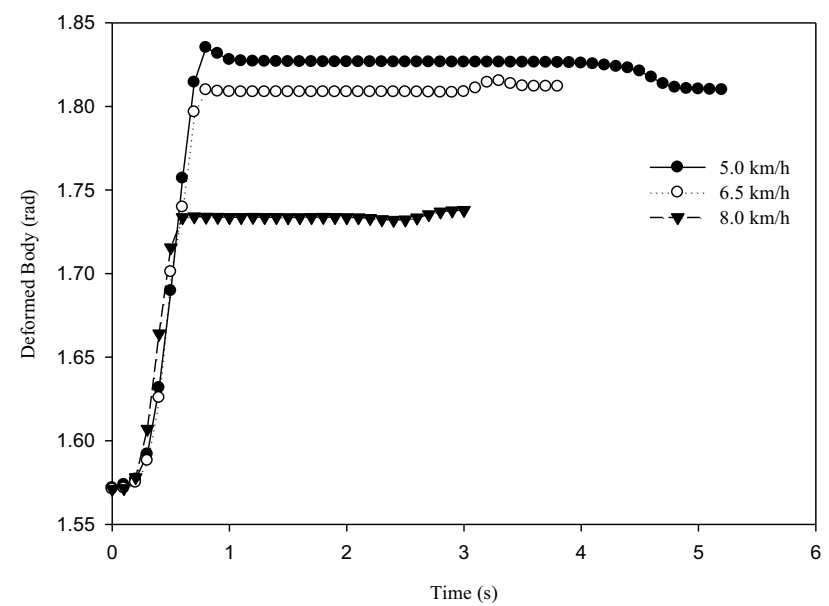

Fig. 9. Deformation of the soil element at the HST 1 during the tractor travelled with the various speeds.

From Figure 9, the deformed body at the $\mathrm{HST}_{1}$ under the different speed was found that the lateral deformation reduced when the speed increased $(6.5$ and $8 \mathrm{~km} / \mathrm{h})$ and the total average difference deformation rates (compared with $5 \mathrm{~km} / \mathrm{h}$ ) were $2.1 \%$ and $4.8 \%$, respectively. This result was in accordance with the research of Shahgholi and Abuali [11]. The maximum shear strain during the front wheel moved over the SST and the 2 HSTs was greater owing to the soil structure was loose (bulk density $\cong 1 \mathrm{~g} / \mathrm{cm}^{3}$ ), so the soil was easier compression and obviously differed from the rear wheel.

\section{Conclusion}

The horizontal shear strain transducer (HST) was enabled to measure the real-time shear strain and mount associated with the stress state transducer (SST) for estimation of the soil compaction process during the external loading was applied. These data would be the advantages of studying and evaluating the operations of the farm tractor and equipment, traffic paths and designing the machinery or the wheel and track to avoid or alleviate the soil 
compaction. Including to the travelling speed was the important parameter on the soil compaction and the deformation of soil.

The authors wish to thank Kahn Charoenphol, Kittinan Chocksawasdikorn and Siwapong Rakmueang who assisted in this study.

\section{References}

1. T.A. Nichols, A.C. Bailey, C.E. Johnson, R.D. Grisso, Trans. ASAE 30, 5 (1987)

2. J.A. Pytka, Int. J. Auto. Tech. 11, 5 (2010)

3. T. Eguchi, T. Muro, J. Terramechanics 44, 5 (2007)

4. N.H. Abu-Hamdeh, R.C. Reeder, Biosyst. Eng. 85, 4 (2003)

5. W. Abdullakasim, M. Koike, T. Takigawa, H. Hasegawa, A. Yoda, B. Bahalayodhin, P. Usaborisut, JSAM 67, 2 (2005)

6. S. Shoop, B. Coutermarsh, D. Diemand, T. Way, Using soil stress state transducers in freezing ground, in Proceedings of the 14th Conference on Cold Regions Engineering, 31 August -2 September 2009, Duluth, Minnesota (2009)

7. J. Pytka, K. Konstankiewicz, Soil Tillage Res. 65, 2 (2002)

8. J. Pytka, J. Dąbrowski, M. Zając, P. Tarkowski, J. Terramechanics 43, 4 (2006)

9. R. Horn, J. Vossbrink, S. Peth, S. Becker, Forest Ecol. Manag. 248, 1-2 (2007)

10. C. Wiermann, T.R. Way, R. Horn, A.C. Bailey, E.C. Burt, Soil Tillage Res. 50, 2 (1999)

11. G. Shahgholi, M. Abuali, J. Terramechanics 59 (2015)

12. J. Pytka, Soil Tillage Res. 59, 1-2 (2001)

13. A. Javadi, G. Spoor, Biosyst. Eng. 88, 3 (2004)

14. W. Hermawan, A. Oida, M. Yamazaki, J. Terramechanics 33, 2 (1996) 